P0117

\title{
STUDENTS IN GOOD MOOD APPEAR SLOWER AND LESS ACCURATE: A PILOT STUDY INVESTIGATING DYNAMIC LIGHTING IMPACT ON STUDENTS' PERCEPTION AND PERFORMANCE
}

\author{
Myriam Aries et al.
}

DOI 10.25039/x46.2019.PO117

from

CIE x046:2019

\author{
Proceedings \\ of the \\ 29th CIE SESSION
}

Washington D.C., USA, June 14 - 22, 2019

(DOI $10.25039 / \times 46.2019)$

The paper has been presented at the 29th CIE Session, Washington D.C., USA, June 14-22, 2019. It has not been peer-reviewed by CIE.

(C) CIE 2019

All rights reserved. Unless otherwise specified, no part of this publication may be reproduced or utilized in any form or by any means, electronic or mechanical, including photocopying and microfilm, without permission in writing from CIE Central Bureau at the address below. Any mention of organizations or products does not imply endorsement by the CIE.

This paper is made available open access for individual use. However, in all other cases all rights are reserved unless explicit permission is sought from and given by the CIE.

CIE Central Bureau

Babenbergerstrasse 9

A-1010 Vienna

Austria

Tel.: +4317143187

e-mail: ciecb@cie.co.at

www.cie.co.at 


\title{
STUDENTS IN GOOD MOOD APPEAR SLOWER AND LESS ACCURATE: A PILOT STUDY INVESTIGATING DYNAMIC LIGHTING IMPACT ON STUDENTS' PERCEPTION AND PERFORMANCE
}

\author{
Aries, M.B.C. ${ }^{1}$, Beute, F. ${ }^{2}$, Fischl, G. ${ }^{1}$ \\ ${ }^{1}$ Jönköping University, Jönköping, SWEDEN, ${ }^{2}$ LightGreen Wellbeing, Eindhoven, NETHERLANDS \\ myriam.aries@ju.se
}

DOI 10.25039/x46.2019.PO117

\begin{abstract}
Dynamic daylight can provide stimulation throughout the day. Since not all building spaces have access to enough daylight, electric lighting solutions can help substituting. The study investigated the effect of two opposite, daily dynamic light patterns to influence students' mood and performance. In a mimicked open office space, 20 second-year students participated in a pilot study where they were exposed to light patterns changing in illuminance level over a day and filled out momentary assessments five times. Hierarchical Linear Models were employed to analyse the effect of light level as well as the timing of the exposure. Positive effects are shown for mood, but only for the pattern with a high morning light level. An afternoon boost may come too late to exert benefits. There are indications for performance-enhancing effects by use of dynamic light conditions, even though students seem to be slower and less accurate when in good mood.
\end{abstract}

Keywords: human centric lighting, learning environment, performance, tuneable lighting

\section{Introduction}

Next to effects of light which enable the visual system to operate, light has 'effects beyond vision' (Commission Internationale de l'Eclairage, 2018). These effects are influenced by the intrinsically photosensitive Retinal Ganglion Cells (ipRGCs) and these photoreceptors are the starting point for regulation of biological functions such as the sleep/wake cycle, alertness, and mood. Several cognitive functions such as learning are impaired if the sleep/wake cycle is not aligned with the internal biological clock (Wright Jr et al., 2006).

\subsection{Light level}

In 1998, Lafrance et al. (1998) found that daytime bright light exposure (9000 to 13000 lux) did not affect subjective alertness, sleep latencies or psychomotor vigilance task (PVT) performance compared to dim light conditions (50 to $150 \mathrm{~lx}$ ) in fatigued or sleep-deprived test persons. However, Cajochen et al. (2000) reported that half of the alerting effects of a bright light condition occurs at ordinary room lighting (circa $100 \mathrm{~lx}$ ). Therefore, Phipps-Nelson et al. (2003) compared a bright light condition of $\sim 1000 \mathrm{Ix}$ vertically to a dim light condition of $<5 \mathrm{Ix}$, again for sleep-deprived subjects. They found that daytime bright light decreases sleepiness and improves performance as soon as the participants were exposed to bright light. More recently, Figueiro et al. (2017) inquired 81 office employees in a field test in both winter and summer. Self-reported measures of mood and sleep, as well as objective measures of light levels and activity rhythms were collected for seven consecutive days. The results showed that receiving low levels of light in the morning (circa $E_{\text {vert }}=100 \mathrm{Ix}$ vertical illuminance) compared to receiving high levels in the morning $\left(E_{\text {vert }}=300 \mathrm{Ix}\right)$ was associated with a reduced transition period from full wakefulness to sleep, especially in winter, and with an increased sleep quality.

The ipRGC-influenced light effects are not only affecting the circadian processes in the human body but acutely enhance alertness and cognitive performance as well. Exposure to high light levels, especially with a high short wavelength content, can increase alertness (e.g., Lockley et al., 2006, Vandewalle et al., 2009, Keis et al., 2014, Cajochen et al., 2019, Hanifin et al., 2019) where efficiency of an exposure of just 18 minutes has already been shown (Vandewalle et al., 2007). 


\subsection{Timed light exposure}

Especially accurately timed light exposure (and not only duration) can promote circadian entrainment and desired acute effects. The alignment between the sleep/wake rhythm and the internal biological was investigated in the study of Wright $\mathrm{Jr}$ et al. (2006). The authors tested cognitive and vigilance performance of 19 healthy men and women in a laboratory for over a month and found that cognitive performance improved (i.e., learning) in the group with a synchronized day/night rhythm and was significantly impaired in the non-synchronized group. They also demonstrated that a light level of circa 25 lux ambient light is enough to expand the range of circadian entrainment in humans. Koutsandréou et al. (2016) stated that research on human cognitive performance employs executive functions, like 'problem solving and reasoning' (high level) or 'working memory', and 'cognitive flexibility' (low level). These functions are critical for mental and physical health as well as for learning and work performance, hence relevant to both children, adolescents, and adults.

\subsection{Dynamic lighting in built environments}

The effect of lighting conditions ( $E_{v e r t}=350 \mathrm{Ix}$ and $1000 \mathrm{Ix}$ ) on the concentration of elementary school children was evaluated by Sleegers et al. (2013). In quasi-experimental field studies, a dynamic lighting system was used using data from 126 pupils spread over two schools. They found a positive indication for the influence of the lighting system on pupils' concentration. Keis et al. (2014) explored exposure to blue-enriched white light ( $E_{\text {vert }}=300 \mathrm{Ix}$; Correlated Colour Temperature $(\mathrm{CCT})=5500 \mathrm{~K})$ in the morning on the performance of 58 high-school students spread over two schools. Compared to standard lighting conditions ( $E_{v e r t}=300 \mathrm{Ix}$; CCT $=3000$ $4000 \mathrm{~K})$, the results showed faster cognitive processing speed and better concentration, but no effects on short-term encoding and retrieval of memories under blue-enriched white light.

The effects of dynamic lighting (horizontal illuminance $E_{h o r}=500-700 \mathrm{Ix} ; \mathrm{CCT}=3000-4700 \mathrm{~K}$ ) on 142 office workers was tested by de Kort and Smolders (2010) in a field study. The data showed no significant differences on, amongst others, self-reported alertness, mental health, sleep quality, or subjective performance, even though the dynamic lighting increased the employees' satisfaction level. Sithravel et al. (2018) tested exactly the same lighting protocol as de Kort and Smolders (2010) in an experimental windowless open-plan workplace in Malaysia. The impact of the light exposure was investigated on, amongst others, psychological indicators for alertness, mood, visual comfort, cognitive and visual task performance and the findings showed that the lighting can act as 'an environmental therapeutic solution in supporting the individuals' psychophysiological wellbeing indicators (p. 1).'

\subsection{Daylight and dynamic electric lighting}

The strongest 'zeitgeber' is usually daylight, with a sunrise indicating the start of a new day for diurnal species like humans. Humans have evolved under the influence of daylight and its 24hour light-dark cycle. Dynamic daylight, with variations ranging from milliseconds to months (Aries et al., 2015), provides various stimulations throughout the day, and access to daylight can reduce stress and increase productivity (Beute and de Kort, 2014). However, not all spaces in a building always have access to enough daylight and sophisticated electric lighting solutions varying in light amount and CCT can help substitute daylight.

Tunable-white lighting is currently one of the biggest trends in dynamic commercial lighting. Tunable white LED-lighting fixtures enable adjustment of light level (luminous flux) and/or colour temperature. The pattern that most tunable systems follow these days is a 'daylight curve' with reduced lighting in the morning and evening and an increased level around noon (while CCT often goes from 'warm' to 'cool' and back to 'warm' again). This daylight course might occur on a day with a clear sky condition, but not on, for example, an overcast day.

\subsection{Aim and objective}

The question is if, especially in cases where daylight is accessible, the tunable system should substitute the daylight situation rather than mimic it. Secondly, is the influence of dynamic lighting with tunable-white lighting beneficial for user performance and well-being? As part of the aim to find the answers to these two complicated questions, the current study's objective was to investigate the effect of two opposite, daily patterns of dynamic light exposure for maintaining or improving students' mood and objective performance. 


\section{Method}

A pilot study was performed in a mimicked open office space in the lighting laboratory of Jönköping University, Sweden. Students in the second year of their Bachelor education took part in the study spread over two full working days with one week in between the study days.

\subsection{Experimental room and light patterns}

The mimicked office room $\left(50 \mathrm{~m}^{2}\right.$, white walls, dark floor) was created using light coloured furniture (desks, book cases) as well as some decorations (plants, curtains). The room's West wall had two luminous panels (Lumlyx Wall LED; $0.50 \times 1.00 \mathrm{~m}$ ) with a green nature image. For the pilot study, commercially available tunable luminaires were used (Fagerhult Notor 78; 50/50). As can be seen in Figure 1, the room had large windows, facing South; however, a large adjacent white building at a short distance prohibited most of the daylight from entering.

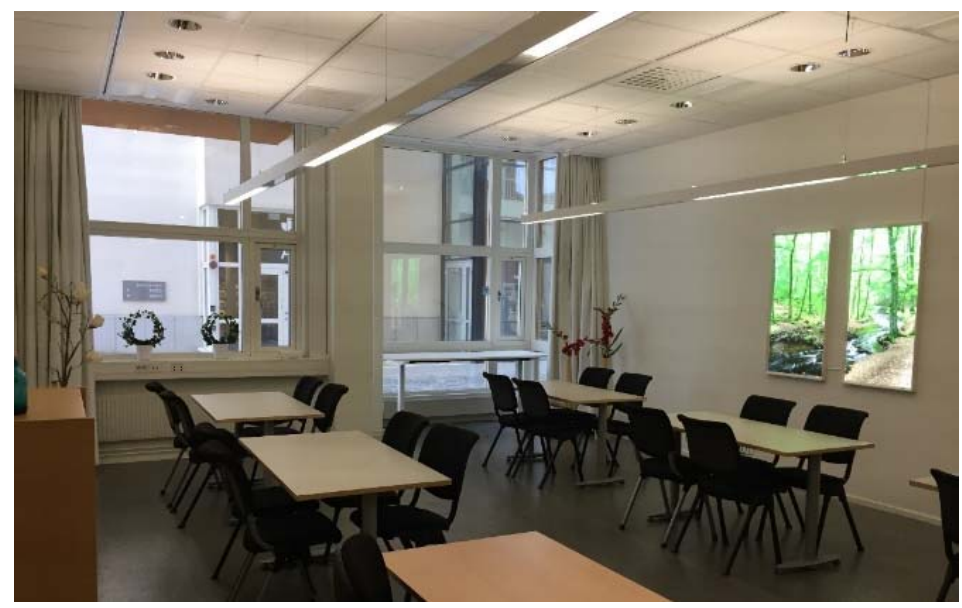

Figure 1 - Experimental set-up for the mimicked open office with lighting in the 'Low' condition

The study involved with two dynamic light patterns that changed in illuminance level over a day, see Figure 2. The colour temperature was kept constant at CCT $=4000 \mathrm{~K}$. Light pattern A (HighLow or $\mathrm{HL}$ ) started at 8:00 with $E_{\text {hor }}=550 \mathrm{~lx}$ at the desk, increased between 8:30 and 11:30 to a maximum desk level of $870 \mathrm{~lx}$, returned to start level between 12:00 and 13:00, and lowered to a minimum level of $240 \mathrm{Ix}$ from 13:30 until 15:30. Light pattern B (Low-High or LH) reversed the minimum and maximum desk levels. The study started at 8:00 and finished at 16:30.

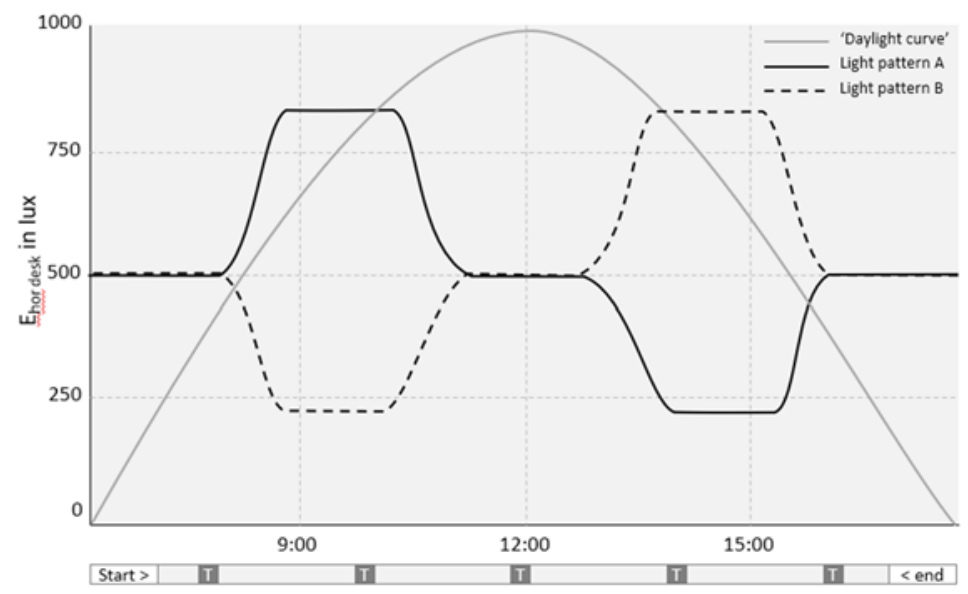

Figure 2 - The two applied light patterns $A$ and $B$ including the task moments with an often suggested 'daylight curve' added as reference. The study started at 8:00 and finished at 16:30 and had five momentary assessments, indicated with ' $T$ ' on the time axis 


\subsection{Participants}

In total, 20 healthy second-year Bachelor students (15 females, 5 males; age $24.6 \pm 0.86$ years) participated in the experiment during one of their regular courses. The participants were informed about the experimental procedure but not about the aim of the research. They all gave their (informed) consent for publication of the data and got a unique ID-code to ensure confidentiality during all phases of the study.

\subsection{Procedure}

On each of the two 8-hour experimental days, the students filled out momentary assessments five times (see ' $T$ ' marks on time axis of Figure 2) regarding 'alertness' using the Karolinska Sleepiness Scale (KSS) by Akerstedt and Gillberg (1990), 'mood' using the Self-Assessment Manikin (SAM) by Lang (Lang, 1980, Bradley and Lang, 1994), 'comfort and satisfaction' using the Office Lighting Survey (OLS) by Eklund and Boyce (1996), as well as performing two cognitive performance tasks: the 3D Mental Rotation task (Shepard and Metzler, 1988) and the Mackworth Clock visual psychomotor vigilance task (Mackworth, 1948), see Figure 3 for examples. Personal and job/study characteristics were collected once, one week prior to the study, accompanied by a short practice session for the performance tasks. The questionnaires were in the English language and created using the web-based method 'PsyToolkit' (Stoet, 2017). Questionnaire access was disabled for use on tablets and smartphones, as it had to be filled in behind the desk.

Due to the nested structure of the momentary assessment data, Hierarchical Linear Models (HLM) were employed to analyse the effect of lighting level as well as the timing of the light exposure on wellbeing and performance. Analyses were performed in STATA 13.1.
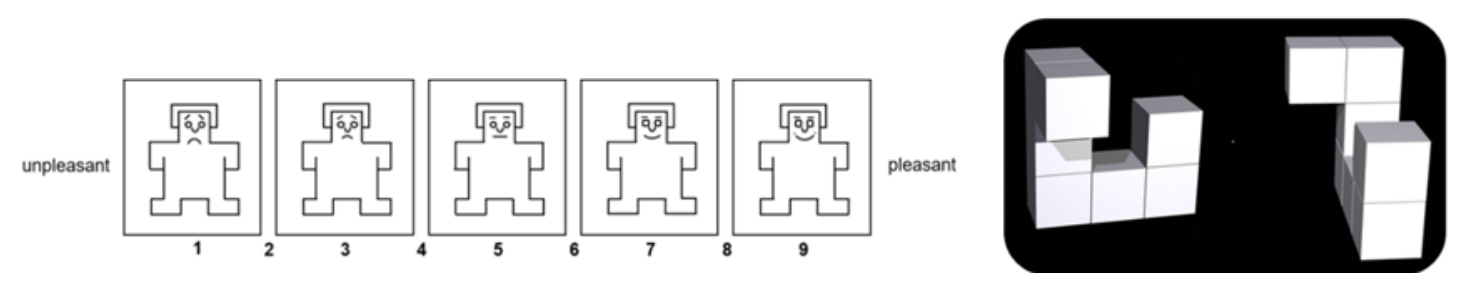

Figure 3 - Left: Scoring of SAM pleasantness on a 9-point scale from unpleasant (1) to pleasant (9); Right: Example of two (identical) shapes during the 3D Mental Rotation task

\section{Results}

In this paper, preliminary results regarding the Self-Assessment Manikin variables 'pleasantness', 'arousal' and 'dominance' as well as on the 'Mental Rotation (MR)' performance (score and reaction time) are discussed for the interaction of Light level and Time of day (morning versus afternoon).

When looking how the variables were related to each other, it was found that all three SAMvariables were significantly related to performance on the MR task (dominance only marginally for MR - score). Counter to expectations, students appeared to be slower and less accurate when they were in a good mood, as indicated by the positive estimate of MT reaction time (MRRT) and the negative estimate for MR - score, see Table 1. No significant relations were found at first sight between light level and any of the SAM-variables.

Table 1 - Overview of Estimates (EST) and Standard Errors (SE) between the SAM (mood) variables, Mental Rotation (MR) outcome variables and Light level

\begin{tabular}{|c|c|c|c|}
\hline & MR - Score & MR - Reaction time & Light level \\
\hline Mood & Est (SE) & Est (SE) & Est (SE) \\
\hline SAM - pleasantness & $-0.11(0.03)^{\star *}$ & $0.001(<0.01)^{* *}$ & $0.08(0.15)$ \\
\hline SAM - arousal & $-0.06(0.03)^{*}$ & $0.0009(<0.01)^{\star *}$ & $0.06(0.14)$ \\
\hline SAM - dominance & $-0.06(0.03)$ & $0.0009(<0.01)^{* *}$ & $-0.01(0.14)$ \\
\hline
\end{tabular}

${ }^{* *} p<.001,{ }^{*} p<.05$, items in italic were marginally significant 


\subsection{Mood}

A Hierarchical Linear Model was run for the three 'mood' variables testing only the 'Low' versus 'High' light exposure in morning (Time $=10: 15)$ versus afternoon $(T=14: 30)$ exposure; meaning without the 'baseline' conditions ( $T=8: 30,12: 00$ and 16:00) to investigate and clarify interaction effects. Generally, the students' mood was better on day 1 compared to day 2.

For SAM - pleasantness, significant main effects were found for Light level (Est $=1.30$; $S E=0.46$; $p=0.004)$ and Time $(E s t=0.90 ; S E=0.46 ; p=0.48)$ as well as for the interaction of Light level ${ }^{*}$ Time $(E s t=-2.3 ; \mathrm{SE}=0.74 ; p=0.002)$. Pleasantness scores were higher in the 'High' light condition and in the morning. Figure 4a. displays how pleasantness developed over the two days. A peak in pleasantness was found during the morning light boost on day 1 (Est margin $=6.15$ ), whereas the light boost on day 2 in the afternoon did not appear to improve this mood variable (Est margin: morning $=4.85$ and afternoon $=4.75$ ).

The SAM - arousal variable showed a significant main effect for Light level (Est $=1.00$; $S E=0.45$; $p=0.025)$ and a significant interaction for Light level*Time (Est $=-1.75 ; S E=0.68 ; p=0.010)$ was found. Arousal was higher in the 'High' light condition than in the 'Low' light condition, and, as can be seen in Figure 4b., the highest arousal level was measured during the morning boost which dissipated over the first day (Est margin: morning $=5.80$ and afternoon $=5.45$ ) whereas the afternoon light boost on day 2 did not appear to increase arousal levels (Est margin: morning=4.80 and afternoon=4.70).

For SAM - dominance, only a marginally significant interaction of Light level*Time appeared (Est=-1.45; SE=0.80; $p=0.069)$. Just as for the two other SAM-variables, a slight increase in dominance was found for the morning light boost (Est margin: morning=5.60 and afternoon=5.50), whereas the afternoon light boost did not appear to influence dominance ratings (Est margin: morning $=4.90$ and afternoon $=4.75$ ). However, this pattern was less clear than for the other two variables, see in Figure 4c.
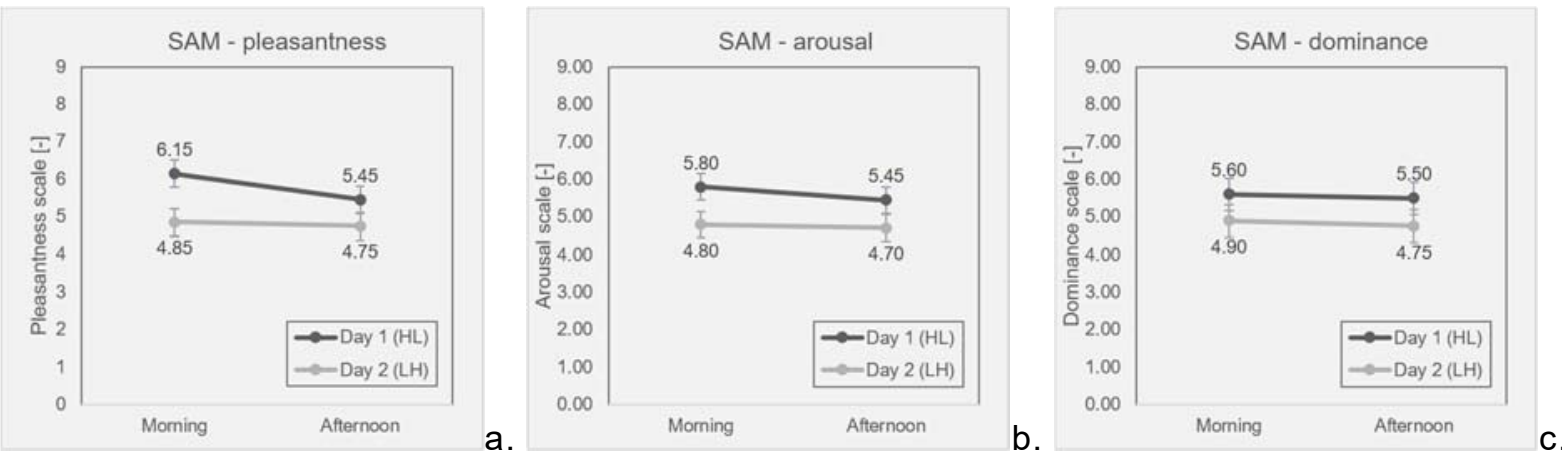

Figure 4 - Interaction of Light level * Time for the three mood variables: a. SAM -pleasantness, b. SAM - arousal, c. SAM - dominance

\subsection{Performance}

Two types of cognitive performance were tested: higher level executive functioning during the Mental Rotation task and vigilance during the Mackworth Clock test. In this paper, only the effects on the mental rotation task will be reported on two variables: score on the task ('percentage correct') and reaction time for correct trials.

A Hierarchical Linear Model was run to explore differences between morning and afternoon exposure to 'High' and 'Low' light levels. A significant main effect of Light level was found for both the score $(E s t=-2.25 ; \mathrm{SE}=0.88 ; \mathrm{p}=0.011)$ and reaction time $(\mathrm{Est}=384.70 ; \mathrm{SE}=88.80$; $p=<0.001)$. For the score, the main effect of Time $(E s t=-2.00 ; S E=0.88 ; p=0.024)$ and interaction of Light level ${ }^{*}$ Time also reached significance $(E s t=4.15 ; S E=1.47 ; p=0.005)$. For the reaction time, the main effect for Time reached only marginal significance (Est=142.80; SE=86.80; $p=0.100)$.

Counter to expectations, on day 1, the score was higher under 'Low' light levels (Est margin $=34.0$ ) than under the 'High' light levels (Est margin=33.8) so better in the afternoon than 
in the morning. On day 2, there was hardly any difference in score between the two light conditions. For the reaction time, the same trend was observed. Reaction time was longer at 'High' light levels (Est margin=2380) compared to the 'Low' light level (Est margin=2138) on day 1 so students became a bit faster with less light. It is, however, just as likely that they became more acquainted with the task.

On day 2, the reaction time was a bit longer in the morning, during the 'Low' light condition (Est margin=1996) and decreased slightly during the 'High' light condition in the afternoon (Est margin=1934) so students became a bit faster with more light or, again, even more acquainted with the task.
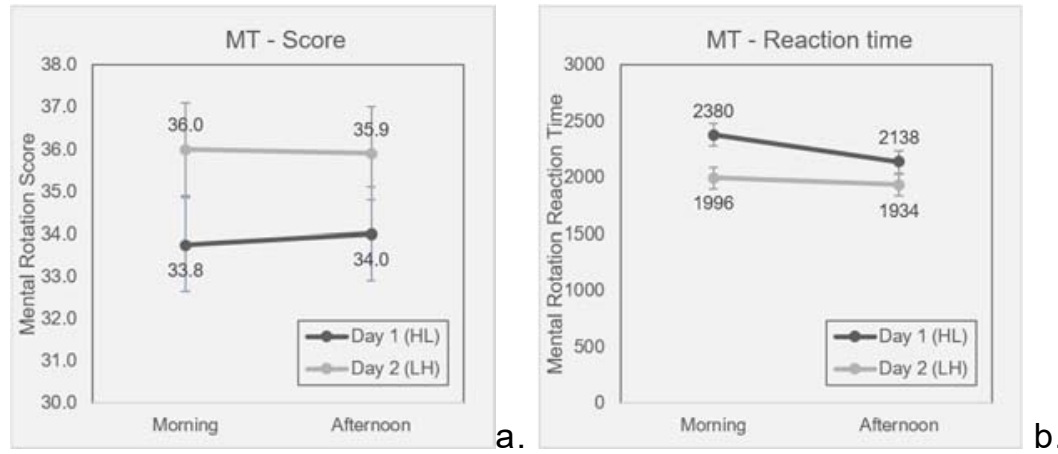

Figure 5 - Interaction of Light level * Time for the Mental Rotation task: a. MT - score, b. MT reaction time

\section{Discussion and conclusions}

Even though in this paper only the data from the peak moments ('High' and 'Low') in afternoon or morning are shown, the data analysis shows indications that a morning light boost did affect students in their mood but was not beneficial for their cognitive performance.

The preliminary outcomes suggest that a 'High' morning level can improve mood, for all three outcome variables: pleasantness, arousal, and dominance, throughout the day whereas a 'High' light level in the afternoon appears to have little to no benefits on mood. A light boost in the afternoon may come too late to exert benefits on pleasantness.

For the cognitive performance task, there appears to be a learning effect appeared as on day 1 the students get faster in the afternoon with less light, on day 2 they get faster in the afternoon with more light, and the reaction time in the morning on day 2 is faster than the reaction time in the afternoon on day 1 . Therefore, it looks like that, for the mental rotation test, students improved their performance with every consecutive assessment. However, this is not totally true for the score variable on the Mental Rotation task where the score in the afternoon of day 2 , under the 'High' light condition, is slightly lower than in the morning.

Despite the difference in start conditions, as the students' mood was better on day 1 compared to day 2, there are indications for performance-enhancing effects by use of dynamic light conditions, even though students seem to be slower and less accurate when in good mood.

Improvements for future studies can be on an even longer practice session or a different or more/less difficult task. Nevertheless, it would also be interesting to investigate whether it is the learning process, the lighting or a change in strategy that explains data. Lafrance et al. (1998) showed that ordinary and high indoor light levels did not affect task performance but found a change in strategy leading to faster reaction times and an increased percentage of errors in the bright light group.

\section{Acknowledgements}

The authors are grateful to the Bertil \& Britt Svenssons stiftelse för belysningsteknik as well as the JU-JTH Internal Strategic Funds for the financial support of this study. They also would like to thank the participants for their input, feedback and efforts for facilitating this project. 


\section{References}

AKERSTEDT, T. \& GILLBERG, M. 1990. Subjective and objective sleepiness in the active individual. Int J Neurosci, 52, 29-37.

ARIES, M. B. C., AARTS, M. P. J. \& VAN HOOF, J. 2015. Daylight and health: A review of the evidence and consequences for the built environment. Lighting Research and Technology, 47, 6-27.

BEUTE, F. \& DE KORT, Y. A. W. 2014. Salutogenic Effects of the Environment: Review of Health Protective Effects of Nature and Daylight. Applied Psychology: Health and WellBeing, 6, 67-95.

BRADLEY, M. M. \& LANG, P. J. 1994. Measuring emotion: the Self-Assessment Manikin and the Semantic Differential. J Behav Ther Exp Psychiatry, 25, 49-59.

CAJOCHEN, C., FREYBURGER, M., BASISHVILI, T., GARBAZZA, C., RUDZIK, F., RENZ, C., KOBAYASHI, K., SHIRAKAWA, Y., STEFANI, O. \& WEIBEL, J. 2019. Effect of daylight LED on visual comfort, melatonin, mood, waking performance and sleep. Lighting Research and Technology.

CAJOCHEN, C., ZEITZER, J. M., CZEISLER, C. A. \& DIJK, D.-J. 2000. Dose-response relationship for light intensity and ocular and electroencephalographic correlates of human alertness. Behav. Brain Res., 115.

COMMISSION INTERNATIONALE DE L'ECLAIRAGE 2018. CIE System for Metrology of Optical Radiation for ipRGC-Influenced Responses to Light. Vienna, Austria: CIE Central Bureau.

DE KORT, Y. A. W. \& SMOLDERS, K. 2010. Effects of dynamic lighting on office workers: First results of a field study with monthly alternating settings. Lighting Research \& Technology, $42,345-360$.

EKLUND, N. H. \& BOYCE, P. R. 1996. The Development of a Reliable, Valid, and Simple Office Lighting Survey. Journal of the Illuminating Engineering Society, 25, 25-40.

FIGUEIRO, M. G., STEVERSON, B., HEERWAGEN, J., KAMPSCHROER, K., HUNTER, C. M., GONZALES, K., PLITNICK, B. \& REA, M. S. 2017. The impact of daytime light exposures on sleep and mood in office workers. Sleep Health, 3, 204-215.

HANIFIN, J. P., LOCKLEY, S. W., CECIL, K., WEST, K., JABLONSKI, M., WARFIELD, B., JAMES, M., AYERS, M., BYRNE, B., GERNER, E., PINEDA, C., ROLLAG, M. \& BRAINARD, G. C. 2019. Randomized trial of polychromatic blue-enriched light for circadian phase shifting, melatonin suppression, and alerting responses. Physiology and Behavior, $198,57-66$.

KEIS, O., HELBIG, H., STREB, J. \& HILLE, K. 2014. Influence of blue-enriched classroom lighting on students' cognitive performance. Trends in Neuroscience and Education, 3, 8692.

KOUTSANDRÉOU, F., NIEMANN, C., WEGNER, M. \& BUDDE, H. 2016. Chapter 13 - Acute Exercise and Cognition in Children and Adolescents: The Roles of Testosterone and Cortisol. In: MCMORRIS, T. (ed.) Exercise-Cognition Interaction. San Diego: Academic Press.

LAFRANCE, C., DUMONT, M., LESPERANCE, P. \& LAMBERT, C. 1998. Daytime vigilance after morning bright light exposure in volunteers subjected to sleep restriction. Physiol Behav, 63, 803-10.

LANG, P. J. 1980. Behavioral treatment and bio-behavioral assessment: computer applications. In: SIDOWSKI, J. B. J., J.H.; WILLIAMS, T.A. (ed.) Technology in mental health care delivery systems. Norwood NJ: Ablex Publishing.

LOCKLEY, S. W., EVANS, E. E., SCHEER, F. A., BRAINARD, G. C., CZEISLER, C. A. \& AESCHBACH, D. 2006. Short-wavelength sensitivity for the direct effects of light on alertness, vigilance, and the waking electroencephalogram in humans. Sleep, 29, 161-8. 
MACKWORTH, N. H. 1948. The Breakdown of Vigilance during Prolonged Visual Search. Quarterly Journal of Experimental Psychology, 1, 6-21.

PHIPPS-NELSON, J., REDMAN, J. R., DIJK, D. J. \& RAJARATNAM, S. M. 2003. Daytime exposure to bright light, as compared to dim light, decreases sleepiness and improves psychomotor vigilance performance. Sleep, 26, 695-700.

SHEPARD, S. \& METZLER, D. 1988. Mental rotation: effects of dimensionality of objects and type of task. J Exp Psychol Hum Percept Perform, 14, 3-11.

SITHRAVEL, R., IBRAHIM, R., LYE, M. S., PERIMAL, E. K., IBRAHIM, N. \& DAHLAN, N. D. 2018. Morning boost on individuals' psychophysiological wellbeing indicators with supportive, dynamic lighting in windowless open-plan workplace in Malaysia. PLOS ONE, 13, e0207488.

SLEEGERS, P. J. C., MOOLENAAR, N. M., GALETZKA, M., PRUYN, A., SARROUKH, B. E. \& VAN DER ZANDE, B. 2013. Lighting affects students' concentration positively: Findings from three Dutch studies. Lighting Research and Technology, 45, 159-175.

STOET, G. 2017. PsyToolkit: A novel web-based method for running online questionnaires and reaction-time experiments. Teaching of Psychology, 44, 24-31.

VANDEWALLE, G., GAIS, S., SCHABUS, M., BALTEAU, E., CARRIER, J., DARSAUD, A., STERPENICH, V., ALBOUY, G., DIJK, D. J. \& MAQUET, P. 2007. Wavelength-Dependent Modulation of Brain Responses to a Working Memory Task by Daytime Light Exposure. Cerebral Cortex, 17, 2788-2795.

VANDEWALLE, G., MAQUET, P. \& DIJK, D. J. 2009. Light as a modulator of cognitive brain function. Trends in Cognitive Sciences, 13, 429-438.

WRIGHT JR, K. P., HULL, J. T., HUGHES, R. J., RONDA, J. M. \& CZEISLER, C. A. 2006. Sleep and wakefulness out of phase with internal biological time impairs learning in humans. Journal of Cognitive Neuroscience, 18, 508-521. 